\title{
INTERACTION OF VITAMIN C AND IRON*
}

\author{
Sean R. Lynch and James D. Cook \\ Division of Hematology \\ Department of Medicine \\ University of Kansas Medical Center \\ Kansas City, Kansas 66103 \\ and \\ Veterans Administration Hospital
Kansas City, Missouri 64128
}

In early studies of food iron absorption, test meals consisted of single foods that had been biosynthetically labeled with radioiron.' Absorption varied considerably with individual food items, and in general, iron derived from animal tissue was more available than iron of vegetable origin. ${ }^{1-3}$ More recently, it has been shown that the percentage absorption of iron from a given food item differs substantially when it is eaten in a meal containing two or more additional foods. ${ }^{2-4}$ For example, soybean iron is much better absorbed than black bean iron if each is eaten separately, but a similar percentage of iron is absorbed from both bean sources when they are eaten together. ${ }^{3}$ Absorption therefore appears to be a property of the overall composition of the meal rather than of the single food item. These studies led to a very important observation. If a small quantity of soluble inorganic iron is added to a biosynthetically labeled vegetable food just before it is eaten, percentage absorption of the two forms of iron is virtually identical.' The same is true of meals containing more than one vegetable food. ${ }^{j-1}$ Therefore, it appears that when several foods are eaten together, nonheme iron destined for absorption behaves as though it were derived from a single common pool. Soluble inorganic iron salts used in fortification also enter this pool.". Iron absorption from it can be measured by determining the size of the pool and the percentage absorption of a soluble radioiron tracer added to the meal. s- $^{-1}$

Similar observations have been made for heme iron, which comes principally from hemoglobin and myoglobin of meat. Heme compounds enter a second common pool and share a set of properties different from those that govern nonheme iron absorption.' For example, heme is not degraded to any degree in the lumen of the gut but is taken up by the mucosal cells with iron still within the porphyrin ring. ${ }^{10}$ Heme iron absorption is relatively independent of other components of the meal; ascorbic acid has no effect. ${ }^{1,12}$ Absorption of heme iron can be measured by adding a small quantity of labeled hemoglobin to a meal just before it is eaten. ${ }^{9}$ Virtually all dietary iron is absorbed from these two pools of heme and nonheme iron. ${ }^{13}$

In attempting to combat iron deficiency, most investigators have focused their attention on nonheme iron, which makes up over $90 \%$ of the iron in an average diet. ${ }^{13}$ The percentage absorption of nonheme iron is only about one-tenth that of heme. Unlike heme iron, the availability of nonheme iron is critically dependent on several factors, some of which enhance and others of which inhibit its uptake. ${ }^{14}$ Many chemical ligands present in food are known to have a powerful influence. For

- This work was supported by contract DSAN-C-0045 from the U.S. Agency for International Development and by Veterans Administration Interagency Agreement IGA V 589 (134)5-79033 from the U.S. Food and Drug Administration. 
example, carbonates, oxalates, phosphates, fiber components, and tannates impair absorption, while ascorbic acid, citric acid, tricarboxylic acids, amino acids, and sugars promote absorption. Of these, ascorbic acid has the greatest influence on iron assimilation.

Initial evidence suggesting that ascorbic acid can enhance iron absorption from certain foods was obtained in studies using meals eaten with and without citrus fruits. ${ }^{1,15-20}$ For example, when $100 \mathrm{ml}$ orange juice containing $40-50 \mathrm{mg}$ ascorbic acid was added to a meal consisting of bread, butter, jam, tea or coffee, and an egg that had been biologically labeled with ${ }^{99} \mathrm{Fe}$, absorption increased from 3.7 to $10.4 \% .^{18}$ More recently, Rossander et al. studied a common Swedish "continental breakfast" and demonstrated that when orange juice containing $70 \mathrm{mg}$ ascorbic acid is consumed with coffee and two wheat rolls, absorption is $2 \frac{1 / 2}{2}$ times higher than that from the same meal without orange juice. ${ }^{20}$

Moore and Dubach were the first to identify ascorbic acid as the cause of the increased absorption seen with meals containing fruit.' They demonstrated a similar increase in absorption with equivalent quantities of ascorbic acid. Their findings have subsequently been confirmed by others. Layrisse et al. demonstrated that nonheme iron absorption from a maize meal was increased severalfold when papaya was added to the meal. " The same degree of enhancement was achieved by adding ascorbic acid equivalent in amount to that contained in the papaya. Thus, although it is possible that there are factors other than ascorbic acid in fruit juices that enhance absorption, there is little doubt that ascorbic acid accounts for the major effect.

\section{Ascorbic Acid as a Nonheme Common Pool Ligand}

Early observations involving fruit juices led to a series of studies of the effect of ascorbic acid on the absorption of various forms of nonheme iron. ${ }^{19.21-31}$ In two of the more recent investigations, ascorbic acid was added to meals prepared from maize, wheat, soya, and rice. ${ }^{24.25}$ The cereal component of each meal had been labeled intrinsically with ${ }^{s 3} \mathrm{Fe}$ by hydroponic cultivation. ${ }^{39} \mathrm{FeCl}_{3}$, used as the extrinsic label for the nonheme pool, was added to the meal in trace quantities either immediately before the meal was eaten or to one of the ingredients before cooking. Supplemental iron in the form of a soluble iron salt, such as $2-5 \mathrm{mg}$ ferric ammonium citrate or 4 $\mathrm{mg}$ ferrous sulfate, was incorporated into some of the meals. Ascorbic acid produced the same increase in absorption of both extrinsic and intrinsic radioiron labels over a wide range of absorption values and ascorbic acid concentrations (FIGURE 1). The composite mean absorption ratio of extrinsic to intrinsic radioiron was 1.13 , a value very close to that of 1.10 reported by Cook $e t$ al. for meals containing no ascorbic acid. ${ }^{3}$ These observations strongly support the conclusion that ascorbic acid acts as a ligand for the common nonheme iron pool and thus enhances absorption of all iron compounds in this pool to an equal extent. An important corollary is that extrinsic tagging allows valid comparisons to be made between meals eaten with and without supplementary ascorbic acid.

A number of ligands in food have a powerful inhibitory effect on absorption from the nonheme iron pool. The interaction of ascorbic acid with two of these, tannates and calcium/phosphate, has been studied. ${ }^{32.31}$ Ascorbic acid reverses the strong inhibitory effect that tea exerts on nonheme iron absorption from cereal-based meals. ${ }^{32}$ The degree of reversal of inhibition is directly proportional to the quantity of added ascorbic acid; absorption in the presence of ascorbic acid and tea may exceed absorption from the basal meal containing neither. The effect of ascorbic acid 


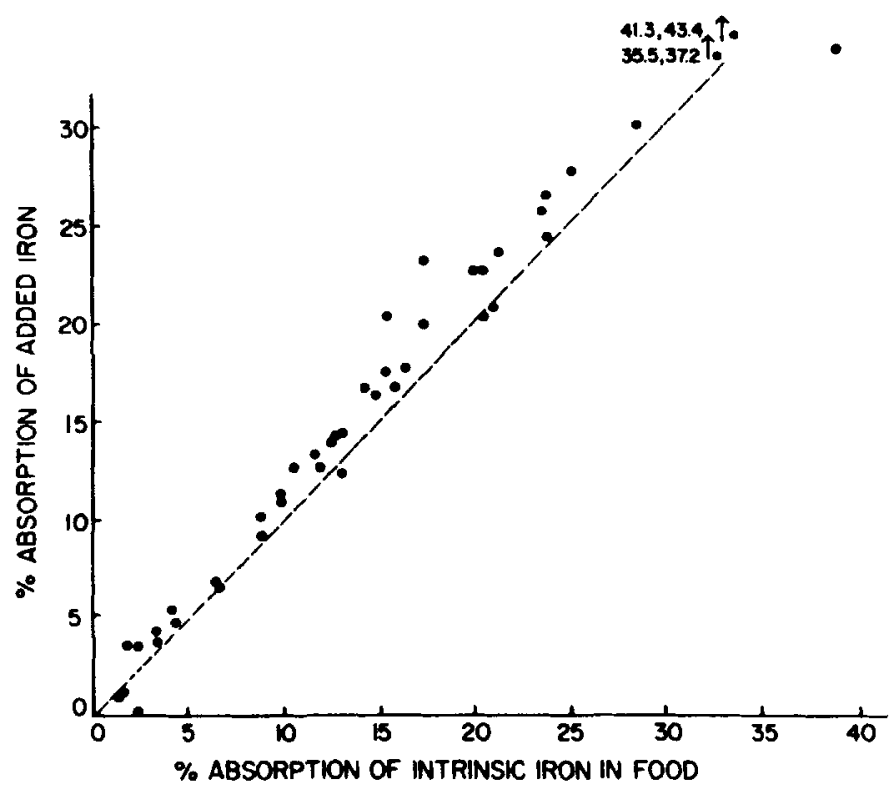

Figure 1. Nonheme iron absorption from test meals tagged simultaneously with intrinsic and extrinsic radioiron labels (see text for explanation).

on the inhibitory influence of calcium/phosphate on iron absorption was studied using a semisynthetic meal." When inorganic calcium/phosphate was omitted from this meal, absorption increased about twofold, but the mean ratio of the meal with ascorbic acid to that without was similar whether or not calcium/phosphate was present. Apparently, ascorbic acid and known inhibitors of iron absorption have an opposite, but additive, effect on absorption from the nonheme common pool and can therefore be considered to act as competitive ligands.

The influence of ascorbic acid on iron absorption from meals containing other absorption promoters is less well defined. For example, meat and fish increase nonheme iron absorption when added to a vegetable meal. Cook and Monsen compared iron absorption from a standard meal containing beef, potatoes, cornmeal, peaches, ice milk, bread, and margarine with that of a semisynthetic meal of similar composition prepared with dextrimaltose, corn oil, and ovalbumin. ${ }^{31}$ Nonheme iron absorption from the standard meal was much higher owing to its content of meat. Absorption from both these meals was enhanced by adding $100 \mathrm{mg}$ of ascorbic acid. However, the mean absorption ratio of the meal with ascorbic acid to that without was 3.19 for the semisynthetic meal and only 1.67 for the standard meal, indicating that the enhancing effects of meat and ascorbic acid are not additive. A similar observation has been made with fish and ascorbic acid. Whereas $100 \mathrm{~g}$ fish increased the absorption of nonheme iron about threefold, "the percentage absorption of iron from a maize meal eaten with $100 \mathrm{~g}$ fish and fresh papayas containing approximately $70 \mathrm{mg}$ ascorbic acid was the same as that from the meal eaten with the papayas alone. ${ }^{19}$ Although it is not possible to draw definitive conclusions from this evidence, these two studies suggest that ascorbic acid and beef or fish are complementary rather than additive in their enhancing properties and that the addition of ascorbic acid to a meal containing meat or fish may have a relatively small influence on the quantity of nonheme iron absorbed. 
Accumulating evidence indicates that the total intake of dietary iron is less important from a nutritional standpoint than the availability of that iron. A model has recently been proposed for estimating dietary iron absorption from any given meal based on the iron status of the individual, the content of heme and nonheme iron, and the content of enhancing constituents. ${ }^{34}$ Of the many factors that have been said to influence iron absorption, only two were considered important enough for inclusion in the method for estimating available dietary iron. Meals were defined as having low, medium, or high iron availability based on the content of meat, poultry, or fish and of ascorbic acid. In this model, $1 \mathrm{~g}$ meat was considered roughly equivalent in its enhancing effect to $1 \mathrm{mg}$ ascorbic acid. Estimates of nonheme iron absorption in subjects with $500 \mathrm{mg}$ iron stores are shown in TABLE 1. The model defines the effect of these substances when added separately to a meal. It is less clear whether their effect is additive when both are contained in the meal. Presumably, the effect of $30-90 \mathrm{~g}$ meat, fish, or poultry and $25-75 \mathrm{mg}$ ascorbic acid would be roughly additive and therefore would place the meal in the high iron availability category, but as previously discussed, this point is not clearly established.

\section{INTERACTION OF ASCORBIC ACID AND CONTAMINANT IRoN}

Not all the iron in a meal is necessarily intrinsic to the food. Chemical assays of Indian diets have consistently revealed iron contents considerably in excess of those determined from food composition tables. ${ }^{14}$ The disparity is believed to represent iron contamination either from the soil or from cooking utensils. The high prevalence of iron deficiency in these geographic areas of the world suggests that this iron is poorly absorbed. Therefore, the potential influence that ascorbic acid has on these less soluble forms of iron could be of considerable nutritional importance. Evaluation of ascorbic acid's effect is difficult because the chemical nature of the extraneous iron has not been identified and because suitable radiolabeled material is difficult to obtain. One study has addressed the problem indirectly. ${ }^{30}$ Two likely food contaminants, ferric oxide, which is the major component of rust derived from cooking utensils, and ferric hydroxide, which forms much of the iron found in soil and unpurified water sources, were radiolabeled and added to a maize porridge meal; both were poorly absorbed, with mean values of $0.01 \%$ and $1.5 \%$, respectively. The addition of $100 \mathrm{mg}$ ascorbic acid increased absorption from ferric oxide to $0.5 \%$ and from ferric hydroxide to $6.7 \%$. Although the relative increase was pronounced, absorption was still inappropriately low in the context of the meal and the irondeficient population studied. This suggests that a significant proportion of each compound remains insoluble and unavailable to the common nonheme iron pool. Moreover, ferric hydroxide was absorbed only half as well as the intrinsic iron con-

TABLE 1

Dietary Iron AvaIlability*

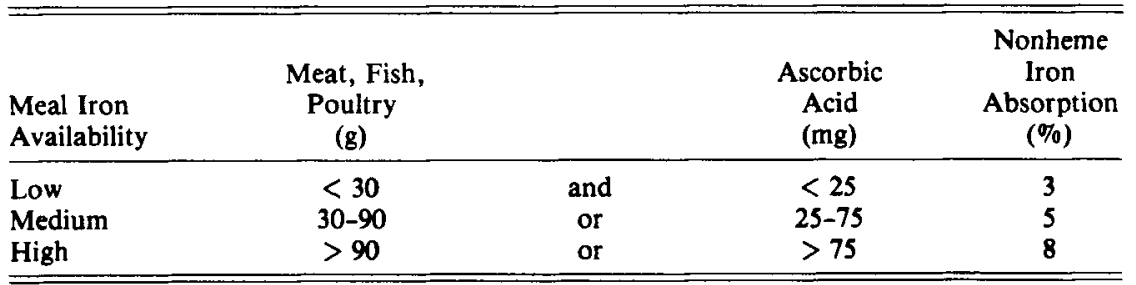

* Based on data of Monsen et al. ${ }^{34}$ 
tained in maize porridge. Presumably most of the contaminating iron contained in food remains relatively unavailable for absorption despite the presence of ascorbic acid.

\section{Quantitative Aspects}

While many observers have noted that percentage nonheme food iron absorption rises with increasing ascorbic acid content of a meal, the quantitative effect of ascorbic acid has been examined rigorously in only two studies, which yielded similar results. ${ }^{27.31}$ In one of them, ascorbic acid-ranging in amounts from 25 to 1,000 $\mathrm{mg}$ - was added to a semisynthetic meal containing $4.1 \mathrm{mg}$ elemental iron. A linear relationship was observed between the absorption ratio of the meal with ascorbic acid to that without and the quantity of added ascorbic acid when both values were plotted on a logarithmic scale. A somewhat different relationship is seen when percentage absorption is plotted against the molar ratio of ascorbic acid to iron using linear scales (FIGURE 2). The response curve has two components. With the molar ratios below 7.5, which corresponds to approximately $100 \mathrm{mg}$ ascorbic acid, there is a proportionately greater effect than with molar ratios above 7.5. It is interesting that when ascorbic acid is taken with pharmacologic doses of ferrous sulfate in the fasting state, a similar two-phase dose-response pattern occurs, although the degree of enhancement and the actual quantity of iron absorbed are very different in the two studies (FIGURE 3). ${ }^{\text {s5 }}$

The factors responsible for the two components of the dose-response curve are unknown, but it is tempting to speculate that the initial component may represent the effect that ascorbic acid has in rendering ferric iron soluble at the alkaline pH of the duodenum (see below). This would account for the relatively small increase in absorption seen when ascorbic acid was added to ferrous sulfate, since a large quantity

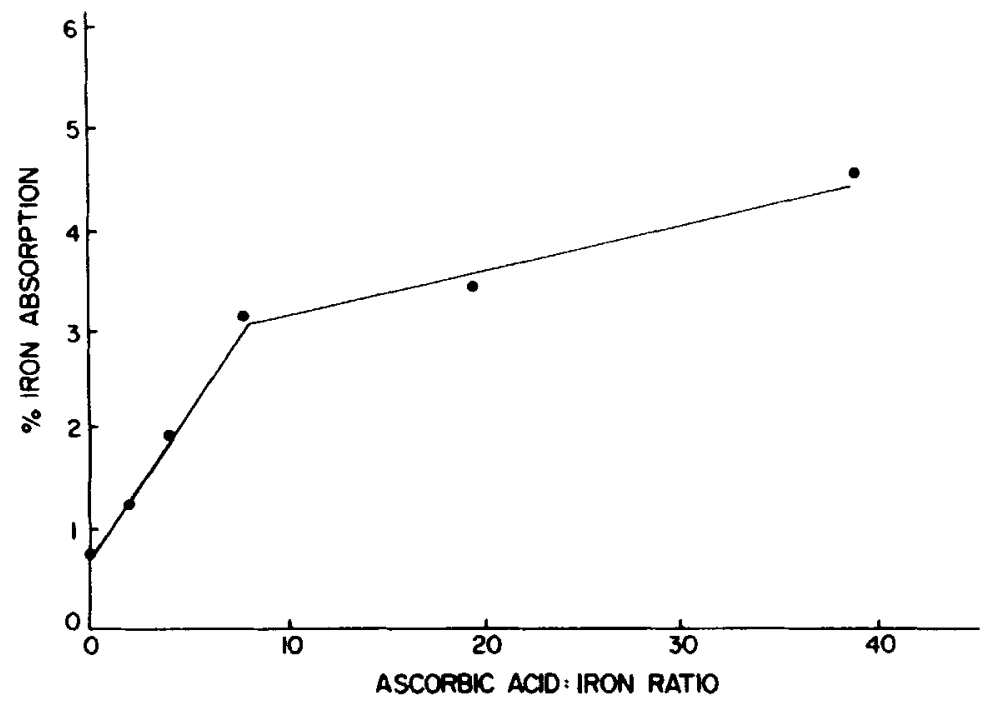

FIGURE 2. The effect of ascorbic acid on iron absorption from a semisynthetic meal, Geometric mean percentage iron absorption is plotted against the molar ratio of ascorbic acid to iron in the meal. (From the data of Cook and Monsen.) ${ }^{31}$ 


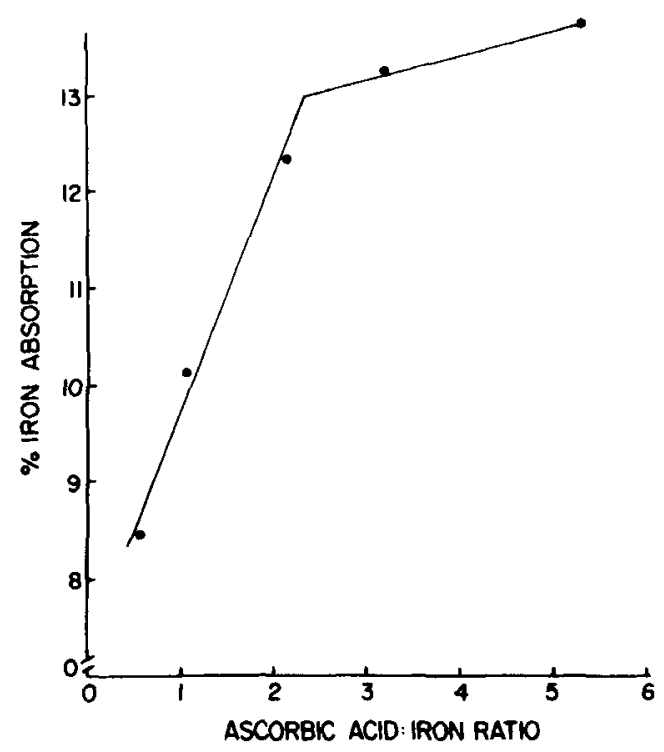

FIGURE 3. The effect of ascorbic acid on iron absorption from $30 \mathrm{mg}$ elemental iron as ferrous sulfate. Percentage iron absorption is plotted against the molar ratio of ascorbic acid to iron. Since there were differences in basal absorption between groups of subjects receiving varying levels of ascorbic acid, the percentage absorption values plotted are those predicted from the absorption ratio with and without ascorbic acid for each group and the geometric mean basal absorption without ascorbic acid of the first group of subjects receiving $\mathbf{5 0} \mathbf{m g}$ ascorbic acid. (Data from Brise and Hallberg.) ${ }^{3 s}$

of iron taken in this form would be expected to arrive at the absorptive surface of the duodenum as the soluble ferrous salt even in the absence of ascorbic acid.

Most of the published evidence dealing with the effect of ascorbic acid on vegetable iron absorption is derived from meals containing maize or rice. If the effect of varying iron status in these studies is removed by relating food iron absorption to a reference dose of ferrous sulfate and ascorbic acid, it is possible to compare the relative absorption of iron in different studies and in different population groups. ${ }^{36}$ We have used the results obtained in a number of different investigations to construct a dose-response curve for iron absorption against molar ratio of ascorbic acid to iron in the meal (FIGURE 4). ${ }^{19.24-26.29,30}$ All values have been adjusted to a reference absorption of $40 \%$, a level that was considered indicative of iron deficiency. Although there is considerable variability between studies, the increase in percentage absorption is again directly proportional to the molar ratio of ascorbic acid to iron in the meal, emphasizing the singular importance of the quantity of ascorbic acid to nonheme iron absorption from vegetable meals.

\section{Mechanism of Action}

Ascorbic acid is effective only if it is present in the meal. In one study, $500 \mathrm{mg}$ ascorbic acid taken with the meal increased absorption about sixfold, whereas the same quantity had little effect when taken four to eight hours prior to the meal. ${ }^{31}$ In most investigations, ascorbic acid has been contained in an uncooked component of 


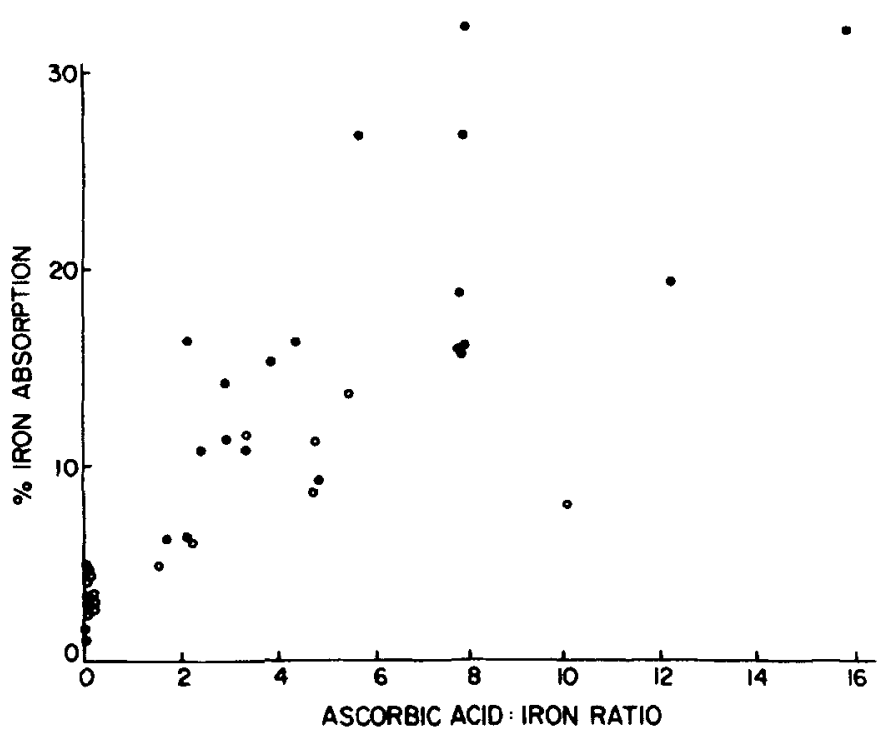

FigURE 4. Enhancing influence of ascorbic acid on vegetable nonheme iron absorption. Mean percentage iron absorption, corrected for reference absorption, is plotted against the molar ratio of ascorbic acid to iron in the meals, Solid circles represent maize meals, and open circles represent rice meals (see text for explanation).

the meal or has been added just before consumption. Under certain circumstances, enhancement was also seen when it was incorporated into one of the ingredients prior to cooking. After boiling, approximately $70 \%$ of 50 - and $100-\mathrm{mg}$ supplements of ascorbic acid remained in the reduced form and significant enhancement of iron absorption was seen. ${ }^{24}$ However, in baked foods, such as soy biscuits and wheat bread, very little ascorbic acid remained in the reduced state and no enhancement of iron absorption occurred.

A better understanding of the probable mode of action of ascorbic acid has been provided by the studies of Conrad and Schade. ${ }^{37}$ When reducing agents are absent from food, iron in the common pool exists in ferric form. Ferric iron has a coordinating valence of 6 , and in an aqueous solution, metal ions are bound to each other through water bridges. Since increases in $\mathrm{pH}$ make more hydroxyl ions available, metallic polymers or precipitated metallic hydroxides are formed, and the iron becomes inaccessible to the mucosal cell. ${ }^{14}$ Conrad and Schade demonstrated that the addition of ascorbic acid to a ferric chloride solution at an acid $\mathrm{pH}$ causes displacement of hydrogen ions from ascorbate and the formation of a purplecolored complex that can be isolated by alcoholic precipitation. This iron chelate remains in solution over a wide $\mathrm{pH}$ range of $2-11$. The reaction however must be initiated at acid pH (FIGURE 5). Both ferric chloride alone and ferric chloride plus ascorbate are insoluble at alkaline $\mathrm{pH}$. Both become progressively more soluble as the $\mathrm{pH}$ is reduced by the addition of hydrochloric acid, and both are totally soluble at a $\mathrm{pH}$ of approximately 2 . As $\mathrm{pH}$ is again raised with sodium hydroxide, ferric chloride is precipitated and very little remains soluble at a $\mathrm{pH}$ above 4 . In contrast, the addition of ascorbic acid to ferric chloride yields a complex of iron that remains completely soluble at a higher $\mathrm{pH}$. The importance of solubility to iron absorption was confirmed in gastrectomized rats. Radioiron absorption was measured from oral 


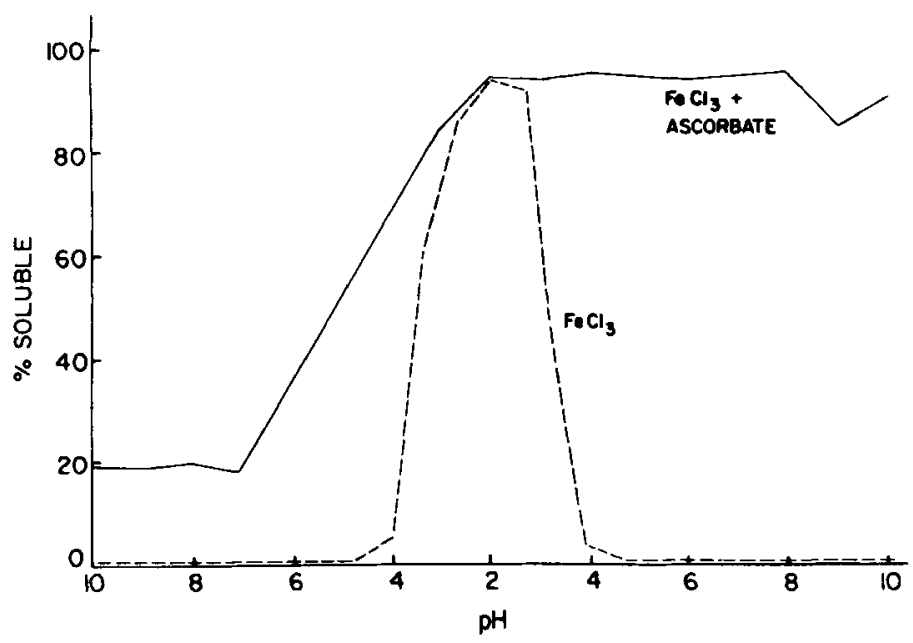

FIGURE 5. Effect of $\mathrm{pH}$ on the solubility of $\mathrm{FeCl}_{3}$ with and without ascorbate. Both $\mathrm{FeCl}_{3}$ (hatched line) and $\mathrm{FeCl}_{3}$ to which an equimolar quantity of ascorbic acid had been added were relatively insoluble in $\mathrm{NaOH}$. As the $\mathrm{pH}$ was reduced by the addition of $\mathrm{HCl}$, both became soluble. $\mathrm{FeCl}_{3}$ was again precipitated by realkalization with $\mathrm{NaOH}$, while $\mathrm{FeCl}_{3}$ with ascorbic acid remained soluble. (After Conrad and Schade.)"

test doses of ferric chloride to which ascorbic acid had been added. Mean percentage absorption for test doses containing ascorbic acid added before and after alkalization was 17 and 5.3, respectively. Similar results were obtained in experiments in which the test doses were instilled directly into the duodenum. When the two iron solutions were introduced into the stomach separately, approximately equal quantities of iron were absorbed.

\section{AsCORBIC ACID Fortification}

In the past, attempts to improve iron nutrition in populations at risk for iron deficiency relied on iron fortification. The efficacy of this approach has been questioned, since added iron enters the nonheme pool of dietary iron and is affected by inhibitors of iron absorption prevalent in this type of diet. If the diet consists predominantly of cereals such as wheat, maize, and rice, which are poor sources of available iron, fortification iron is also poorly absorbed. Improvement in iron status may only be possible if fortification iron is added in a form less affected by dietary constituents or if a substance is added to the diet that renders both food iron and fortification iron more available. The former approach has led to the use of iron with ethylenediamine tetraacetic acid (EDTA) in pilot fortification studies. The latter might be made feasible by adding ascorbic acid to the diet.

Although theoretically attractive, a number of obstacles have been encountered in using ascorbic acid for dietary fortification. The initial investigations were based on the premise that optimal results would be obtained by adding both ascorbic acid and fortification iron to the diet to ensure a sufficiently large pool of nonheme iron on which ascorbic acid could act. ${ }^{24}$ However, in selecting a suitable food vehicle for dual fortification, a number of practical problems were encountered. It is desirable 
for such a vehicle to be eaten in approximately the same quantities by all individuals. Ideally, the vehicle should not be added prior to cooking, since ascorbic acid is largely inactivated when subjected to the high temperatures used for baking. Common salt seemed to be the most suitable vehicle, but discoloration occurred when ascorbic acid and various iron compounds were added to it simultaneously. ${ }^{25,26}$ The discoloration was particularly pronounced when cheaper grades of salt were used and after storage in hot, humid conditions. Nevertheless, it is possible to fortify common salt with $0.1 \%$ iron as ferric phosphate $\left(\mathrm{FePO}_{4}\right)$ and $1.25 \%$ ascorbic acid. This product can be stored under all but the most extreme tropical conditions provided that $2.5 \%$ starch is incorporated to retard the development of discoloration. However, FePO, is a relatively insoluble compound, and the influence of ascorbic acid on its absorption is variable. When added to rice and maize meals prior to cooking, it appears to enter the common pool completely, and the enhancement achieved by the addition of ascorbic acid is the same for FePO, as for intrinsic iron or added ferrous sulfate. ${ }^{26}$ In contrast, when FePO, is added to a maize meal immediately before it is eaten, it remains relatively unavailable for absorption even when large quantities of ascorbic acid are present. ${ }^{29}$ Cane sugar has been examined as a fortification vehicle, ${ }^{29}$ but it is also unsatisfactory since it is commonly taken in tea and coffee and any soluble iron present produces a black discoloration due to the precipitation of tannins. ${ }^{32}$ Finally, ascorbic acid fortification is expensive when compared with iron fortification, and this is an important consideration in developing countries.

\section{AsCorbic ACID Supplementation}

The recommended dietary allowance for ascorbic acid is currently set at $45 \mathrm{mg}$ daily. However, it has been suggested that this quantity is not adequate for optimal health and that very large doses of ascorbic acid are desirable. Intakes as high as 2-3 $\mathrm{g}$ daily have been reported to be beneficial in reducing the frequency and severity of the common cold and possibly in reducing the risk of cancer. ${ }^{31}$

The long-term effects of such megadose quantities of ascorbic acid on iron balance in man are not known. In a limited survey among Americans living in the northwestern United States, Cook and Monsen found ascorbic acid intakes ranging between 0 and $2,000 \mathrm{mg}$ with a mean of $280 \mathrm{mg}$. $^{31}$ Based on studies with a semisynthetic meal containing no meat, they concluded that $280 \mathrm{mg}$ ascorbic acid would produce a twofold increase in iron absorption if taken with breakfast and a threefold increase if taken in divided doses during the day.

These estimates probably represent the maximum possible effect of ascorbic acid, and the actual increase in iron absorption may be considerably less for several reasons. Ascorbic acid is effective in promoting food iron absorption only if taken with the meal; some or all of the supplementary ascorbic acid may be taken separately from meals. Population groups eating large quantities of ascorbic acid are drawn more commonly from the affluent sections of society where the consumption of animal foods is relatively high. The estimates of the enhancing effect of ascorbic acid on iron absorption were based on a diet containing no meat or fish. ${ }^{31}$ However, as indicated above, ascorbic acid may have a much smaller effect on percentage iron absorption from meals containing animal foods. The final consideration in estimating the potential hazards of megadose levels of ascorbic acid intake relates to the doseresponse effect of ascorbic acid. From the relationship between iron absorption and the molar ratio of ascorbic acid to iron (FIGURE 2), $100 \mathrm{mg}$ ascorbic acid may represent a near maximal effect. If this is so, the estimated increase in absorption produced by a daily intake of $280 \mathrm{mg}$ ascorbic acid in a meat-containing diet would be 
approximately $20 \%$ if the supplement were eaten with breakfast and slightly less than $40 \%$ if taken in three divided doses with each meal of the day. Support for this argument has been obtained in pilot studies, which have shown remarkably little longterm effect on iron stores in volunteer subjects taking $2 \mathrm{~g}$ ascorbic acid over 24 months. ${ }^{38}$

\section{SUMMARY}

Food iron is absorbed by the intestinal mucosa from two separate pools of heme and nonheme iron. Heme iron, derived from hemoglobin and myoglobin, is well absorbed and relatively little affected by other foods eaten in the same meal. On the other hand, the absorption of nonheme iron, the major dietary pool, is greatly influenced by meal composition. Ascorbic acid is a powerful enhancer of nonheme iron absorption and can reverse the inhibiting effect of such substances as tea and calcium/phosphate. Its influence may be less pronounced in meals of high iron availability-those containing meat, fish, or poultry. The enhancement of iron absorption from vegetable meals is directly proportional to the quantity of ascorbic acid present. The absorption of soluble inorganic iron added to a meal increases in parallel with the absorption of nonheme iron, but ascorbic acid has a much smaller effect on insoluble iron compounds, such as ferric oxide or ferric hydroxide, which are common food contaminants. Ascorbic acid facilitates iron absorption by forming a chelate with ferric iron at acid $\mathrm{pH}$ that remains soluble at the alkaline $\mathrm{pH}$ of the duodenum. High cost and instability during food storage are the major obstacles to using ascorbic acid in programs designed to combat nutritional iron deficiency anemia.

\section{REFERENCES}

1. Moore, C. V. \& R. Dubach. 1951. Observations on the absorption of iron from foods tagged with radioiron. Trans. Assoc. Am. Physicians 64: 245-256.

2. LAYrisSE, M. \& C. Martinez-Torres. 1971. Iron absorption from food. Iron supplementation of foods. In Progress in Hematology. E. B. Brown \& C. V. Moore, Eds. 6: 137-160. Grune \& Stratton, Inc. New York, N.Y.

3. MARTINEZ-ToRRES, C. \& M. LAYRISSE. 1973. Nutritional factors in iron deficiency: food iron absorption. In Clinirs in Haematology. S. T. Callender, Ed. 2: 339-352. W. B. Saunders \& Co. London, Philadelphia, Toronto.

4. Martinez-Torres, C., I. Leets, M. Renzi \& M. Layrisse. 1974. Iron absorption by humans from veal liver. J. Nutr. 104: 983-993.

5. Cook, J. D., M. Layrisse, C. Martinez-Torres, R. Walker, E. Monsen \& C. A. Finch. 1972. Food iron absorption measured by an extrinsic tag. J. Clin. Invest. 51: 805-815.

6. Björn-Rasmussen, E., L. Hallberg, B. Magnusson, L. Rossander, B. Svanberg \& B. Arvidsson. 1976. Measurement of iron absorption from composite meals. Am. J. Clin. Nutr. 29: 772-778.

7. Björn-Rasmussen, E., L. Hallberg \& R. B. Walker. 1972. Food iron absorption in man. I. Isotopic exchange between food iron and inorganic iron salts added to food: studies on maize, wheat and eggs. Am. J. Clin. Nutr. 25: 317-323.

8. Björn-Rasmussen, E., L. Hallberg \& R. B. Walker. 1973. Food iron absorption in man. II. Isotopic exchange of iron between labelled foods and between a food and an iron salt. Am. J. Clin. Nutr. 26: 1311-1319.

9. MARTINEZ-TorRes, C. \& M. LAYRisse. 1971. Iron absorption from veal muscle. Am. J. Clin. Nutr. 24: 531-540.

10. Weintraub, L. R., M. B. Weinstein \& H.-J. Huser. 1968. Absorption of hemoglobin 
iron: the role of a heme-splitting substance in the intestinal mucosa. J. Clin. Invest. 47: 531-539.

11. Callender, S. T., B. J. Mallett \& M. D. Smith. 1957, Absorption of haemoglobin iron. Br. J. Haematol. 3: 186-192.

12. Turnbull, A. L., F. Cleton \& C. A. Finch. 1962. Iron absorption. IV. The absorption of hemoglobin iron. J. Clin. Invest. 41: 1897-1907.

13. Björn-Rasmussen, E., L. Hallberg, B. Isaksson \& B. Arvidsson. 1974. Food iron absorption in man. Applications of the two-pool extrinsic tag method to measure heme and nonheme iron absorption from the whole diet. J. Clin. Invest. 53: 247-255.

14. Bothweli, T. H., R. W. Charlton, J. D. Cook \& C. A. Finch. 1979. Iron Metabolism in Man. Blackwell Scientific Publications. Oxford, England.

15. Steinkamp, R., R. Dubach \& C. V. Moore. 1955. Studies in iron transportation and metabolism. VIIl. Absorption of radioiron from iron-enriched bread. Arch. Intern. Med. 95: 181-193.

16. Callender, S. T. \& G. T. Warner. 1968. Iron absorption from bread. Am. J. Clin. Nutr. 21: $1170-1174$.

17. Elwood, P. C., D. Newton, J. D. Eakins \& D. A. Brown. 1968. Absorption of iron from bread. Am. J. Clin. Nutr. 21: 1162-1169.

18. Callender, S. T., S. R. Marney, Jr. \& G. T. Warner. 1970. Eggs and iron absorption. Br. J. Haematol. 19: 657-665.

19. Layrisse, M., C. Martinez-Torres \& M. Gonzalez. 1974. Measurement of the total daily dietary iron absorption by the extrinsic tag model. Am. J. Clin. Nutr. 27: 152-162.

20. Rossander, L., L. Hallberg \& E. Bjorn-Rasmussen. 1979. Absorption of iron from breakfast meals. Am. J. Clin. Nutr. 32: 2484-2489.

21. Pirzio-Biroli, G., T. H. Bothwell \& C. A. Finch. 1958. Iron absorption. Il. The absorption of radioiron administered with a standard meal in man. J. Lab. Clin. Med. 51: $37-48$.

22. Apte, S. V. \& P. S. Venkatachalam. 1965. The effect of ascorbic acid on the absorption of iron. Indian J. Med. Res. 53: 1084-1086.

23. Kuhn, I. N., M. Layrisse, M. Roche, C. Martinez \& R. B. Walker. 1968. Observations on the mechanism of iron absorption. Am. J. Clin. Nutr. 21: 1184-1188.

24. Sayers, M. H., S. R. Lynch, P. Jacobs, R. W. Charlton, T. H. Bothwell, R. B. WALKER \& F. MAYET. 1973. The effects of ascorbic acid supplementation on the absorption of iron in maize, wheat and soya. Br. J. Haematol, 24: 209-218.

25. Sayers, M. H., S. R. Lynch, R. W. Charlton, T. H. Bothwell, R. B. Walker \& F. MAYET. 1974. Iron absorption from rice meals cooked with fortified salt containing ferrous sulphate and ascorbic acid. Br. J. Nutr. 31: 367-375.

26. Sayers, M. H., S. R. Lynch, R. W. Charlton, T. H. Bothwell, R. B. Walker \& F. MAYET. 1974. The fortification of common salt with ascorbic acid and iron. Br. J. Haematol. 28: 483-495.

27. BIÖRN-RASMUSSEN, E. \& L. HALlBERg. 1974. Iron absorption from maize. Effect of ascorbic acid on iron absorption from maize supplemented with ferrous sulphate. Nutr. Metab. 16: 94-100.

28. Layrisse, M., C. Martinez-Torres, M. Renzy \& I. Leets. 1975. Ferritin iron absorption in man. Blood 45: 688-698.

29. Disler, P. B., S. R. Lynch, R. W. Charlton, T. H. Bothwell, R. B. Walker \& F. MAYET. 1975. Studies on the fortification of cane sugar with iron and ascorbic acid. $\mathrm{Br}$. J. Nutr. 34: 141-151.

30. Derman, D., M. Sayers, S. R. Lynch, R. W. Charlton, T. H. Bothwell \& F. Mayet. 1977. Iron absorption from a cereal-based meal containing cane sugar fortified with ascorbic acid. Br. J. Nutr. 38: 261-269.

31. COOK, J. D. \& E. R. Monsen. 1977. Vitamin C, the common cold, and iron absorption. Am. J. Clin. Nutr. 30: 235-241.

32. Disler, P. B., S. R. Lynch, R. W. Charlton, J. D. Torrance, T. H. Bothwell, R. B. WALKER \& F. MAYET. 1975. The effect of tea on iron absorption. Gut 16: 193-200.

33. Layrisse, M., C. Martinez-Torres \& M. Roche. 1968. The effect of interaction of various foods on iron absorption. Am. J. Clin. Nutr. 21: 1175-1183. 
34. Monsen, E. R., L. Hallberg, M. Layrisse, D. M. Hegsted, J. D. Cook, W. Mertz \& C. A. FinCh. 1978. Estimation of available dietary iron. Am. J. Clin. Nutr. 31: 134-141.

35. Brise, H. \& L. Hallberg. 1962. Effect of ascorbic acid on iron absorption. Acta Med. Scand. Suppl. 171(376): 51-58.

36. COOK, J. D., M. LAYrisse \& C. A. Finch. 1969. The measurement of iron absorption. Blood 33: 421-429.

37. Conrad, M. E. \& S. G. Schade. 1968. Ascorbic acid chelates in iron absorption: a role for hydrochloric acid and bile. Gastroenterology 55: 35-45.

38. CooK, J. D. 1980. Unpublished observations.

\section{Discussion}

W. R. Holus (Life Systems Incorporated, Melville, N.Y.): Just some questions on protocol. Were your experiments on humans or in animals?

S. R. LYNCH: They were done on humans.

W. R. HoluB: Oh, then two questions. One is on the biosynthetic sources of ${ }^{59} \mathrm{Fe}$. Were the total assays of iron compared?-so that when you compared meat to vegetable sources, were you really giving equimolar ratios of total iron and not just radioactive iron? That is one question. The second question is, How were the different foods prepared?-because that would make a significant difference. For example, if the grains were cooked or simply ground up instead of sprouted, that would make the availability of iron quite different.

S. R. LYNCH: The amounts of iron naturally present in the meals were not changed in most studies. We fed what we thought were representative meals for the people being studied, so that in most instances, there was of course very much less heme iron than there was nonheme iron. The nonheme iron forms a very much bigger pool in the diet. No attempts were made to change this situation.

In some of the studies where iron supplements were being investigated, an iron salt was added in addition to the nonheme iron already present.

All of the meals were cooked, and this of course has important effects, particularly on the ascorbic acid. Experiments were done in which ascorbic acid was added prior to the cooking procedure. If the food was baked, virtually all the ascorbic acid was oxidized and its addition had no effect. If it was boiled, as is more common in most of the developing countries, not all of the ascorbic acid was lost-perhaps 30 or $40 \%$ was oxidized-and an enhancing effect was still seen. If you add enough, you can still see a very significant effect.

H. Sprince (Veterans Administration Medical Center, Coatesville, Penn.); I missed your point about the optimal pH for the solubility of ferric chloride salts in the presence of ascorbic acid. What is that roughly? Is it pH 4 ?

S. R. LYNCH: What I tried to show was that ferric chloride itself is really only soluble at acid pH. If you add ascorbic acid to a ferric chloride suspension at an alkaline $\mathrm{pH}$, it makes very little difference to iron solubility; but if you first lower the $\mathrm{pH}$ to the acid range, you form a complex of iron and ascorbic acid that remains soluble as the $\mathrm{pH}$ is raised again. We think that as the $\mathrm{pH}$ falls in the stomach, the complex is formed; and it then remains soluble once the higher $\mathrm{pH}$ of the duodenum is reached. $\mathrm{pH} 4$ ?

H. SpRINCE: What was the optimal pH at which this effect first set in? Was it

S. R. LYNCH: In the in vitro experiment I described, they actually took it down to 2. That probably isn't necessary, but I don't know exactly how low you would have to go. 
H. SPRINCE: I'm just wondering too what would have happened if, instead of ascorbic acid, you had used the dehydro form. Has that been considered in this in vitro system?

S. R. LYNCH: I'm not aware of that if it has.

H. SPRINCE: What I'm really saying is, What is the effect of dehydroascorbic acid in solubilizing ferric salts?

S. R. LYNCH: The only evidence that I can really quote in relation to that question is the effect of baking a meal. Baking doesn't totally oxidize ascorbic acid but at least removes virtually all of the dehydro form. We don't see any improvement in absorption then.

UNIDENTIFIED SPEAKER: I guess we have seen two effects: one is reduction of iron, and the other is chelation. Probably the first thing that happened was reduction; and then after that, chelation and return to iron three. The ascorbic acid may also be oxidized to dehydroascorbic and diketogulonic acids. Could you discuss the possibility of iron chelation to the latter two compounds?

S. R. LYNCH: Our work does not provide an answer to this question, and I don't think it has been examined carefully. It has been stated, especially in the older literature, that iron must be in the reduced form to be absorbed. This may well not be true, and the observation may have reflected only the better solubility of ferrous compounds at the $\mathrm{pH}$ of the duodenum. Therefore, I think that all one can say is that iron and ascorbic acid form a soluble complex that makes iron available to the mucosal cell. This does not necessarily imply that the iron must be in the reduced form.

L. Howard (Albany Medical College, Albany, N.Y.): Dr. Lynch, just a small, practical question. You mentioned already that the absorption of the more watersoluble salts of iron is not greatly improved by ascorbic acid. Does that mean that therapeutic tablets that combine ferrous sulfate with vitamin $\mathrm{C}$ are nonsense?

S. R. LYNCH: Yes, $I$ think it probably does mean almost that. There is some improvement in the absorption seen with ferrous sulfate. Brise and Hallberg have studied the effect of large doses of vitamin $\mathrm{C}$ on the absorption of a 30-mg dose of ferrous sulfate, and you do see an increase in absorption up to a little less than $11 / 2$ times. I think that this relatively small effect is unimportant because there is a large quantity of available iron already present. You don't -need the small increase in percentage absorption, and the addition of ascorbic acid is, of course, expensive. Thus it is probably not appropriate to recommend the use of such combinations. Furthermore, as you increase absorption, you also increase side effects by the same degree. So I think, all in all, there really isn't any reason for adding ascorbic acid to soluble ferrous salts.

L. M. KLeVay (Human Nutrition Laboratory, U.S. Department of Agriculture, Grand Forks, N. Dak.): It's interesting that the beneficial effect of ascorbic acid on iron absorption contrasts with the impairment of copper absorption that has been found in several species. I just bring this up now because I don't think any of the other speakers are going to get to it.

J. G. BIERI (National Institutes of Health, Bethesda, Md.): What's the relative effectiveness of animal protein vs. ascorbic acid in the absorption of the inorganic iron? Would it be more feasible to promote more animal protein intake than to go through the ascorbic acid route?

S. R. LYNCH: I think both are important. Dr. Monsen and her colleagues recently proposed a model in which they tried to look at this. The conclusion that they reached was that $1 \mathrm{mg}$ of ascorbic acid was roughly equivalent in its effect to $1 \mathrm{~g}$ of animal protein. 